\title{
Evaluation of thermodynamic efficiency of biowaste gasification
}

\author{
K. J. Ptasinski \\ Eindhoven University of Technology, The Netherlands
}

\begin{abstract}
Concerns about global climate change and depletion of fossil fuels have increased interest in biomass and other renewable energy sources. Due to shortage of clean biomass much attention is recently devoted to various biowaste streams. This paper focuses on biowaste gasification, where the produced synthesis gas can be subsequently used to produce biofuels, including Fischer-Tropsch hydrocarbons, methanol and hydrogen. The thermodynamic efficiency of biowaste gasification is evaluated for various feedstocks using energy and exergy indicators. It is shown that exergetic efficiency is lower than corresponding energetic efficiencies. Modification of biomass gasification is proposed to improve process efficiency. Finally, the conversion efficiency of overall chains biomass-to-biofuel is discussed.

Keywords: renewable energy, biomass, waste gasification, exergy analysis.
\end{abstract}

\section{Introduction}

With declining petroleum resources and concerns about climate change, more attention is now being directed towards sustainable production of chemicals and transportation fuels. In this respect, biomass has neutral $\mathrm{CO}_{2}$ impact and is the only current sustainable source of carbon. The most promising biomass-to biofuel route is a two-stage process involving production of syngas from biomass gasification, followed by synthesis of transportation fuels, involving Fischer-Tropsch hydrocarbons, methanol and hydrogen. It was previously demonstrated that the gasifier is one of the least-efficient unit operation in the whole biomass-to-biofuels chain. Therefore, an analysis of the gasifier alone can substantially contribute to the efficiency improvement of the whole biofuel production technology.

The introduction of bioenergy raises many technological and also ethical questions, particularly in developing countries. In industrialized countries the 
agriculture is quite advanced and some countries can produce enough biomass for food as well as for biofuels. However, in some very dense populated countries, particularly The Netherlands, there is land shortage for biomass cultivation to cover all needs. On the other hand, the food production in many developing countries is rather low and these countries should first focus on producing edible biomass for food before they use biomass for biofuels. Moreover, the average conversion efficiency of sunlight into chemical energy in biomass through photosynthesis is about $0.5-1.0 \%$, which is much lower compared to other forms of renewable energy such as photovoltaics or wind energy [1].

Therefore, the application of biomass wastes is very attractive not only from energy point of view but also for ecological reasons. The development of very efficient biomass-to-biofuels processes is currently one of the major challenges for renewable energy technology. One of the difficulties with measuring energy efficiency is the lack of consensus on the evaluation of performance of energy systems. The traditional analysis based on the First Law of Thermodynamics shows only the mass and energy flows and does not take into account how the quality of the energy and material streams degrades through the process. In this paper the exergy analysis, which is based on the Second Law of Thermodynamics is used to analyze the conversion of biomass to biofuels.

The main purpose of this paper is to study the gasification efficiency of biomass wastes. The paper starts with an explanation of evaluation of thermodynamic efficiency using the exergy concept. In section 3 , the exergetic efficiency of gasification of different biomass wastes is evaluated and compared. Modification of biomass gasification to improve the efficiency is proposed in section 4. Finally, exergetic efficiency of biowaste-to-biofuel chains is presented in section 5 .

\section{Thermodynamic efficiency using exergy concept}

The method of exergy analysis is often considered as a new method to analyze energy systems and is applied in different fields of engineering and science. The exergy concept is based on the Second Law of Thermodynamics and defined as the maximum amount of work that can be obtained from a material stream, heat stream or work interaction with respect to environmental conditions [2]. The environment is considered as a medium composed of common substances existing in abundance within the Earth's atmosphere, oceans and crust. The reference state is usually taken to be at standard temperature $\left(T_{\mathrm{o}}=298 \mathrm{~K}\right)$ and pressure $\left(p_{\mathrm{o}}=1 \mathrm{~atm}\right)$. Some reference species include $\mathrm{CO}_{2}, \mathrm{O}_{2}, \mathrm{~N}_{2}$, having a mole fraction of $0.0003,0.2099,0.7903$ in dry air, respectively.

Exergy, contrary to the energy concept, is not conserved in a process. The sum of all entering exergy streams is always higher than that of all leaving streams and the difference is called exergy loss or irreversibility $I$. Irreversibility represents the internal exergy loss in a process as the loss of quality of materials and energy due to dissipation. It relates also to entropy production $\Pi$ in the system according to the following equation: 


$$
I=T_{o} \Pi
$$

Among the different forms of exergy, three forms are the major contributors to the total exergy and they are: thermal exergy, work exergy, and exergy of materials. The exergy balance of a process can be represented in the following form using exergy values of all streams entering and leaving the process:

$$
\sum_{I N} E_{j}+E^{Q}+E^{W}=\sum_{O U T} E_{k}+I
$$

where $\sum_{I N} E_{j}$ and $\sum_{O U T} E_{k}$ are exergy flows of all entering and leaving material streams, respectively, $E^{Q}$ and $E^{W}$ are the sums of all thermal exergy and work interactions involved in a process.

\section{Exergetic efficiency of biomass gasification}

Current gasifiers, such as fluidized bed and downdraft, are applied to gasify various biomass feedstocks as well as coal. The exergetic efficiency of gasification depends on the chemical composition of a fuel and in this section the efficiency of different feedstocks is compared and benchmarked against gasification of coal. These biomass feedstocks include various types of biomass and biowastes, such as wood, vegetable oil, sludge and manure, which vary greatly in chemical composition, energy content, ash and moisture content. Table 1 shows proximate and ultimate analyses for coal and the biofuels that are considered [3].

Table 1: Proximate and ultimate analysis of various biofuels.

\begin{tabular}{|l|l|l|l|l|l|l|l|l|}
\hline Fuel & \multicolumn{4}{|l|}{ Proximate analysis (wt\%) } & \multicolumn{4}{l|}{ Ultimate analysis (wt\% of organic } \\
& Mraction) \\
\hline & Moisture & Ash & $\begin{array}{l}\text { Organic } \\
\text { fraction }\end{array}$ & C & H & O & N & S \\
\hline Coal & 11.5 & 8.50 & 80.0 & 78.2 & 4.93 & 13.3 & 1.45 & 1.69 \\
\hline Vegetable oils & 0.0 & 0.0 & 100.0 & 75.4 & 11.7 & 12.9 & 0.0 & 0.0 \\
\hline Straw & 12.7 & 6.37 & 80.9 & 48.9 & 5.97 & 43.9 & 0.82 & 0.15 \\
\hline Treated wood & 14.6 & 4.44 & 81.0 & 51.5 & 6.03 & 41.3 & 1.22 & 0.09 \\
\hline Untreated wood & 19.8 & 1.84 & 78.4 & 50.8 & 6.06 & 42.7 & 0.36 & 0.07 \\
\hline Grass/plants & 24.2 & 5.46 & 70.3 & 49.7 & 6.00 & 42.7 & 1.32 & 0.18 \\
\hline Sludge & 32.5 & 25.72 & 41.8 & 50.2 & 7.09 & 34.9 & 5.63 & 1.77 \\
\hline Manure & 43.6 & 17.20 & 39.2 & 50.2 & 6.50 & 34.6 & 5.19 & 0.85 \\
\hline
\end{tabular}

The efficiencies of gasification of these fuels are shown in fig. 1. The efficiencies are either based on energy (lower heating value LHV) or exergy (chemical and chemical and physical exergy) and are defined as the ratio of the exergy (energy, respectively) of syngas to exergy (energy, respectively) of biomass. It is assumed that biomass is gasified using air and syngas leaves the gasifier at chemical equilibrium at the gasifier temperature. 


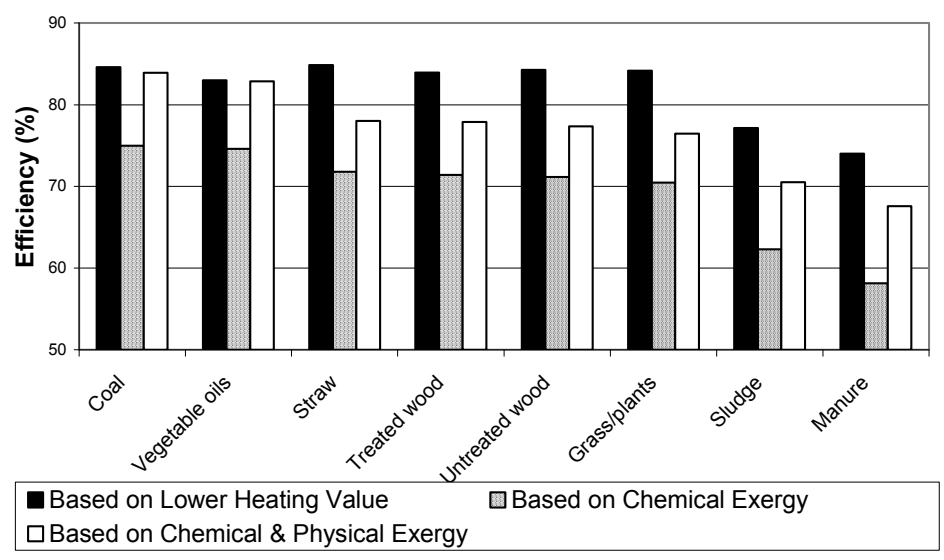

Figure 1: Gasification efficiencies of various biomass feedstocks.

The energetic efficiencies of sludge and manure gasification are much lower compared to that of other fuels, including coal. It is mainly due to high moisture content in these biowastes that results in rather low gasification temperature, about $600^{\circ} \mathrm{C}$. All other fuels contain less moisture and can be gasified at much higher temperatures, in the range of $650-850^{\circ} \mathrm{C}$. This figure shows that the efficiencies of coal and vegetable oil based on chemical exergy are higher that of other fuels. A similar conclusion can be drawn with respect to the efficiency based on the chemical and physical exergy. For all fuels, exergetic efficiencies are lower than energetic efficiencies; this means that less useful work (exergy) can be obtained from syngas compared to heat (LHV). The exergetic efficiencies are more meaningful than the energetic ones if syngas is used to produce transportation fuels, as the final product is work obtained from a vehicle.

The exergetic efficiency of wet biowastes, such as sludge and manure, can be improved by using the enthalpy of syngas for drying of biowastes. In this case the gasifier system consists of three units: biomass dryer operating at a temperature of $100^{\circ} \mathrm{C}$ placed before the gasifier, the gasifier and heat exchanger placed downstream the gasifier where the product gas is cooled down and produces the heat needed for the dryer. The temperature of the product gas leaving this gasification system is lower than the gasification temperature as heat is removed for the evaporation of water.

The gasification system is analysed for the sludge, which is dried from its initial moisture content of $32.5 \%$ to water percentages varying from $30 \%$ to $11 \%$. This decreases the final temperature of the product gas from $600^{\circ} \mathrm{C}$ to temperatures between 514 and $297^{\circ} \mathrm{C}$. Fig. 2 shows the effect of drying the sludge on the overall efficiency of the gasification system. It is clear that decreasing the moisture content of the biomass entering the gasifier increases all efficiencies of the process. The largest benefit is obtained when the sludge is dried from $32.5 \%$ to $19 \%$ moisture. 


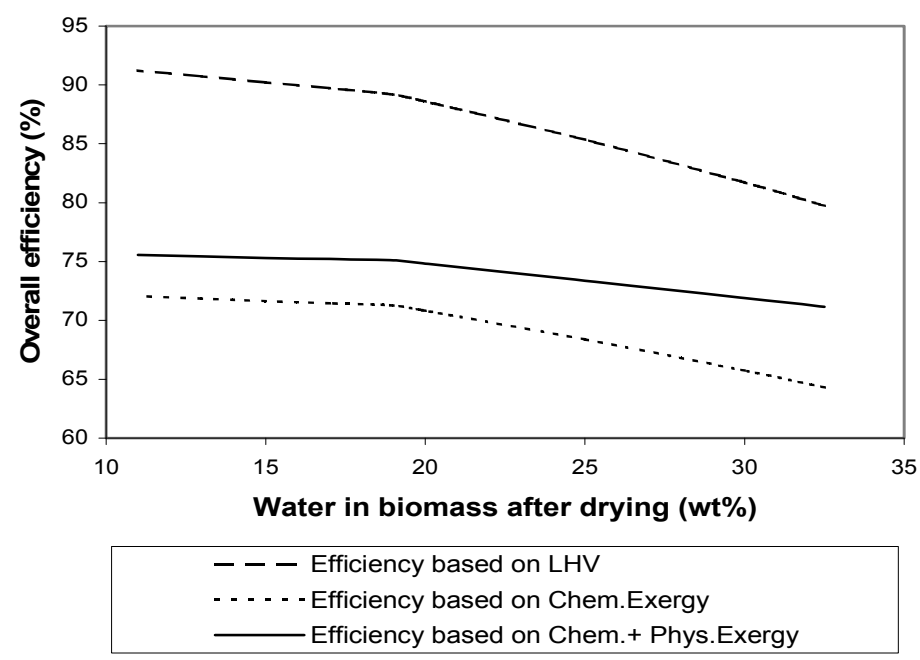

Figure 2: Improvement of gasification efficiency by pre-drying of sludge.

\section{Improvement of gasification using torrefaction}

The properties of biomass and biowastes can be improved by a process known as torrefaction, which comprises thermal pre-treatment in an inert gas at temperatures from 230 to $300^{\circ} \mathrm{C}$ [4]. The torrefied biomass has a lower $\mathrm{O} / \mathrm{C}$ and $\mathrm{H} / \mathrm{C}$ ratio due to the removal of water and carbon dioxide, as shown for beach wood in fig. 3, the so called van Krevelen diagram [5].

During torrefaction, the biomass partly devolatilises; this leads to a decrease of mass, but the initial energy content of the biomass is almost completely preserved in the solid product (fuel). Typically, torrefied biomass retains $70-90 \%$ of the original wood mass whereas the heating value increases by $5-25 \%$ and this way the energy density is increased by $20-40 \%$. Torrefied biomass has a brown color and its properties are changing towards that of coal. Torrefaction is particularly attractive for a mixture of biowastes as it leads to a uniform chemical composition of the final product, e.g. in pellets.

Biomass torrefaction can be used as the pre-treatment step before biomass gasification and different systems are possible, as indicated in table 2 .

Torrefaction can be coupled with the circulating fluidised bed (CFB) gasifier (IIab) where the volatiles from the torrefaction reactor are not utilized. The hot product gases from the gasifier are physically quenched with cold gas to a temperature of $800^{\circ} \mathrm{C}$. Steam produced in Heat Recovery Steam Generator (HRSG) is partially used to provide heat for the torrefaction process and partially exported. The pressure of the steam generated in the HRSG is tailored for controlling the torrefaction temperature: 45 bar for torrefaction at $250^{\circ} \mathrm{C}$ and 90 bar for torrefaction at $300^{\circ} \mathrm{C}$. 


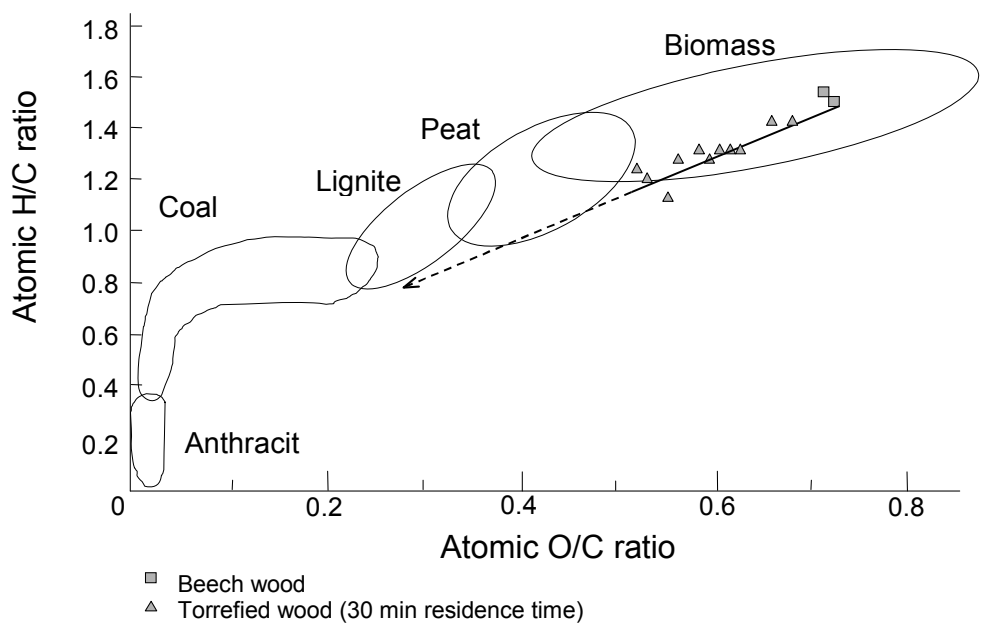

Figure 3: Change of composition of biomass in torrefaction.

In a more advanced system (see table 2 and fig. 4), wood torrefaction can be coupled with entrained flow (EF) gasifier (IIIab) [5]. In this system, the volatiles from the torrefaction reactor are introduced in the top of the gasifier to induce a "chemical quench". The conventional biomass gasification of wood (without torrefaction) in CFB gasifier (I) is used as a reference for efficiency comparison.

Table 2: Exergetic efficiency of torrefaction coupled with biomass gasification.

\begin{tabular}{|l|c|c|c|c|c|}
\hline $\begin{array}{l}\text { Efficiency } \\
(\%)\end{array}$ & $\begin{array}{c}\text { Air-blown } \\
\text { CFB } \\
\text { gasification } \\
\left(950^{\circ} \mathrm{C}\right)\end{array}$ & \multicolumn{2}{|c|}{$\begin{array}{c}\text { Torrefaction and air-blown } \\
\text { CFB gasification }\left(950^{\circ} \mathrm{C}\right)\end{array}$} & \multicolumn{2}{|c|}{$\begin{array}{c}\text { Torrefaction and } \mathrm{O}_{2} \text {-blown } \\
\text { EF gasification }\left(1200^{\circ} \mathrm{C}\right)\end{array}$} \\
\cline { 2 - 6 } & $\begin{array}{c}\text { No } \\
\text { torrefaction } \\
(\mathrm{I})\end{array}$ & $\begin{array}{c}\text { Torrefaction } \\
\text { at } 250^{\circ} \mathrm{C} \\
(\mathrm{IIa})\end{array}$ & $\begin{array}{c}\text { Torrefaction } \\
\text { at } 300^{\circ} \mathrm{C} \\
(\mathrm{IIb})\end{array}$ & $\begin{array}{c}\text { Torrefaction } \\
\text { at } 250^{\circ} \mathrm{C} \\
(\mathrm{III})\end{array}$ & $\begin{array}{c}\text { Torrefaction } \\
\text { at } 300^{\circ} \mathrm{C} \\
(\mathrm{IIIb})\end{array}$ \\
\hline $\begin{array}{l}\text { Gas: } \\
\text { chemical } \\
\text { exergy }\end{array}$ & 68.6 & 67.2 & 56.2 & 66.8 & 72.4 \\
\hline $\begin{array}{l}\text { Gas: physical } \\
\text { exergy }\end{array}$ & 1.4 & 1.2 & 1.3 & 0.8 & 1.0 \\
\hline Steam & 6.2 & 5.5 & 4.3 & 4.1 & 2.1 \\
\hline Overall & 76.2 & 73.9 & 61.8 & 71.7 & 75.5 \\
\hline
\end{tabular}

Table 2 shows that the efficiency for oxygen-blown EF gasification of torrefied wood (IIIb) is quite comparable to that of air-blown CFB gasification of wood (I), and slightly lower than that if torrefied wood is produced at $250^{\circ} \mathrm{C}$ (case IIIa). However, the highest amount of chemical exergy retained in the product gas is observed for case IIIb; this is very convenient for the subsequent chemical synthesis of transportation biofuels. 


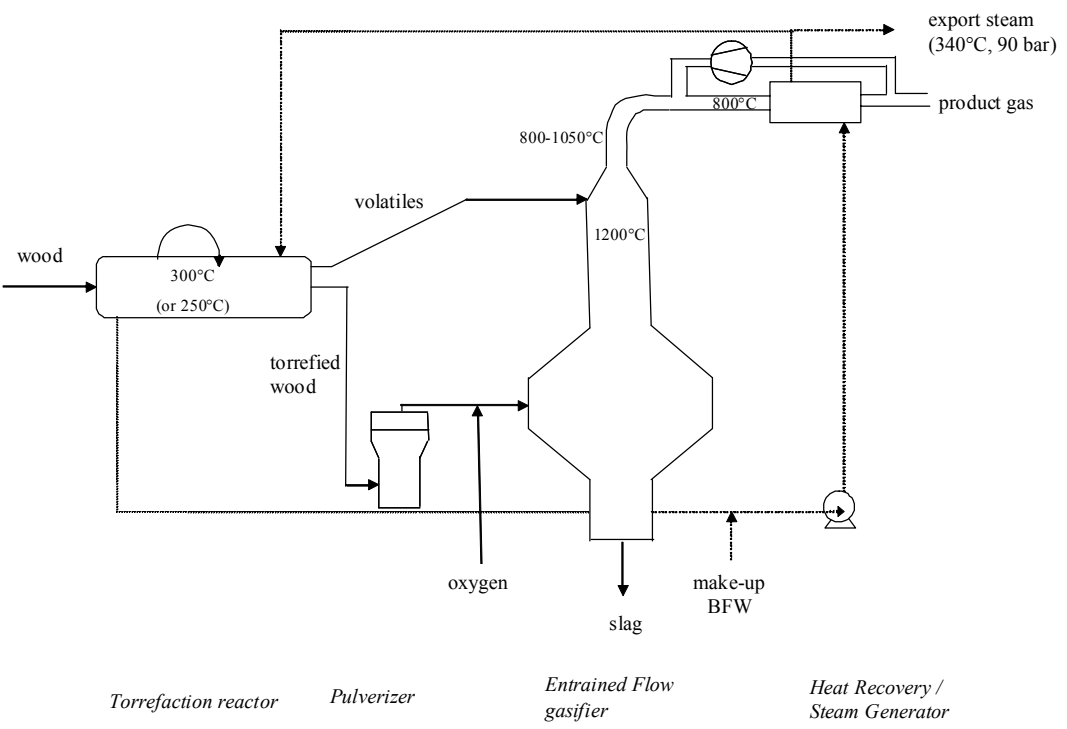

Figure 4: Torrefaction coupled with oxygen-blown EF gasifier.

\section{Exergetic efficiency of biofuels from biomass gasification}

Currently the most promising route to sustainable transportation fuels is based on production of syngas from biomass gasification, followed by synthesis of biofuels [6]. Production of potential transportation fuels, including Fischer-Tropsch hydrocarbons, methanol and hydrogen from various biomass feedstocks and biowastes is attractive using this method [7].

Fig. 5 shows a schematic diagram of conversion process for production of biofuels from biomass gasification. A wide range of biomass sources, such as traditional agricultural crops, residues from agriculture and foresting, sewage sludge and municipal solid wastes can be used to make biofuels. These biomass feedstocks vary greatly in chemical composition, energy content, ash and moisture content and the best and economically attractive feedstock can be selected.

For wet biomass feedstocks, drying is needed to adjust the moisture content into a desired value. In the gasifier, biomass reacts at high temperature (typically $900^{\circ} \mathrm{C}$ ) with air, oxygen or/and steam to produce syngas, which contains $\mathrm{CO}, \mathrm{H}_{2}$, $\mathrm{CO}_{2}, \mathrm{CH}_{4}, \mathrm{H}_{2} \mathrm{O}$ and $\mathrm{N}_{2}$. $\mathrm{CO}$ and $\mathrm{H}_{2}$ are the building reagents for synthesis of different biofuels. Subsequently syngas is cleaned from undesired components produced in the gasifier, such as tars, $\mathrm{H}_{2} \mathrm{~S}, \mathrm{NH}_{3}$ and $\mathrm{HCl}$. The synthesis of most biofuels is usually a high-pressure process and therefore syngas is compressed up to the desired reactor pressure. Before the biofuel synthesis the ratio between CO and $\mathrm{H}_{2}$ in syngas is adjusted in a water gas shift (WGS) reactor, according to the chemical reaction:

$$
\mathrm{CO}+\mathrm{H}_{2} \mathrm{O}=\mathrm{H}_{2}+\mathrm{CO}_{2}
$$




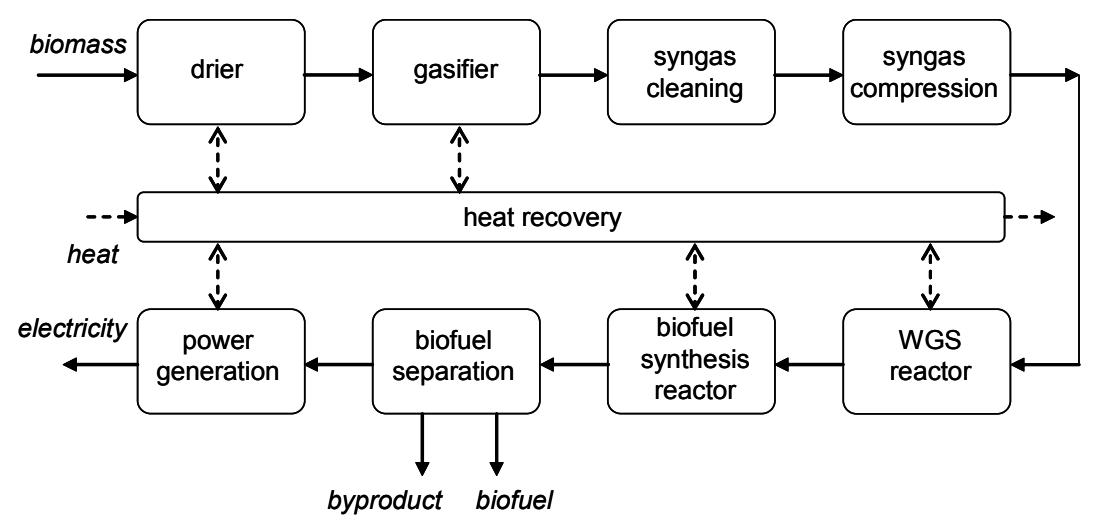

Figure 5: Schematics of biomass-to-biofuels production.

In a catalytic synthesis reactor specific biofuels, such as Fischer-Tropsch hydrocarbons or methanol are produced. In case of hydrogen production, only WGS reactors are sufficient and no specific synthesis reactors are needed. The biofuel formed in the synthesis reactor is separated from by-products in a separation unit. The remaining by-products contain usually high energy content and they can be used to produce electricity in a power generation unit or process steam in the heat integration unit. The heat recovery is particularly needed as in the overall process synthetic gas is cooled from a high temperature in the gasifier to much lower temperature in the biofuel synthesis reactor.

The process illustrated in fig. 5 can be used to produce Fischer-Tropsch (FT) hydrocarbons from sawdust. In this process 57 ton/h of sawdust is converted into 5.6 ton/h of liquid FT products and 4.0 MW of electricity is also produced. On weight basis the net output of hydrocarbon fuel is only $15.2 \%$. The exergy analysis shows that the biomass feed contains $210.8 \mathrm{MW}$ exergy and the final liquid products contain $72.9 \mathrm{MW}$ with co-production of $4.0 \mathrm{MW}$ of electricity.

Methanol may play a significant role as a synthetic fuel for the future as it has higher energy content per volume than the other alternative fuels. Generally, methanol can be produced from any organic source including biomass and municipal wastes according to the flowsheet shown in fig. 5. Using sewage sludge as a feedstock $(50,000$ tons dry solids/year), the plant can produce 4300 tons methanol/year. On weight basis the net output of methanol is only $8.6 \%$ but on the exergy basis $22.8 \mathrm{MW}$ of sludge exergy is converted into $15.4 \mathrm{MW}$ of methanol exergy.

Various biomass resources, such as wood, vegetable oil and manure can be also used to produce hydrogen. Currently, hydrogen is the most promising energy carrier for the future. Using wood as a feedstock the plant converts $1000 \mathrm{~kg} / \mathrm{h}$ biomass into $76 \mathrm{~kg} / \mathrm{h}$ hydrogen and $1330 \mathrm{~kg} / \mathrm{h} \mathrm{CO}_{2}$-rich gas as the by-product. The net output of hydrogen on mass basis is thus $7.6 \%$ only. The exergy analysis indicates that $4.64 \mathrm{MW}$ of wood exergy is transformed into $2.54 \mathrm{MW}$ exergy of hydrogen and $0.61 \mathrm{MW}$ of $\mathrm{CO}_{2}$-rich gas. 
Fig. 6 shows the exergetic efficiency of various biomass-to-biofuel routes that are discussed above but also including hydrogen produced from biomass using biochemical processes such as fermentation and anaerobic digestion. The exergetic efficiency for hydrogen-from-natural-gas process by steam methane reforming (SMR) is also reported in this figure, as a typical value for fossil fuels [8]. All reported biomass routes have lower exergetic efficiency compared to fossil fuels. The highest efficiency is for hydrogen-from-biomass processes from high quality feedstocks, such as wood or vegetable oil. It is demonstrated that biomass gasification is the least-efficient process step in the overall biomass-to-biofuels route.

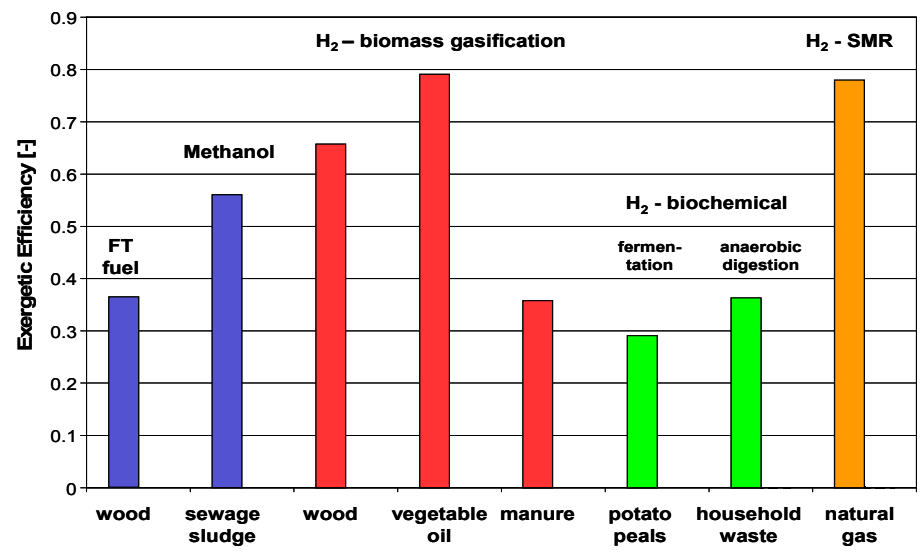

Figure 6: Exergetic efficiency of various biomass-to-biofuels processes.

\section{Conclusion}

Biomass as a gasifier fuel can provide the world more renewable transportation fuels. However, major limitations are shortage of land and water and competition with food production. Therefore application of biowastes is very attractive not only from energy point of view but also for ecological reasons.

The most promising large-scale production of biofuels consists of gasification of biomass (biowastes) and subsequent conversion into liquid (gaseous) fuels, such as FT hydrocarbons, methanol, and hydrogen. In all investigated processes the largest exergy losses are due to biomass gasification, which are intrinsic. Wet wastes (e.g. sludge, manure) are attractive feedstocks in many countries due to limited availability of so-called clean biomass. However, exergetic efficiency of conversion of wet biowastes is quite low as gasification at optimum conditions is not always possible.

The efficiency of gasification of wet biowastes can be improved by using the enthalpy of the syngas for drying of biomass. The properties of biomass, even of dry biowastes, can be improved by a thermal pre-treatment called torrefaction. In this process, the $\mathrm{O} / \mathrm{C}$ ratio in biomass is reduced, in addition to the higher energy density; this results in the improved thermodynamic performance of gasification. 


\section{References}

[1] Herman, W.A., Quantifying global exergy resources. Energy, 31, pp. 1349-1366, 2006.

[2] Szargut, J., Morris, D.R. \& Steward, F.R., Exergy Analysis of Thermal, Chemical and Metallurgical Processes, Springer Verlag: Berlin, 1988.

[3] Ptasinski, K.J., Prins, M.J. \& Pierik, A., Exergetic evaluation of biomass gasification. Energy, 32, pp. 568-574, 2007.

[4] Bourgois, J. \& Guyonnet, R., Characterization and analysis of torrefied wood. Wood Science Technology, 22, pp. 143-155, 1988.

[5] Prins, M.J., Ptasinski, K.J. \& Janssen, F.J.J.G., More efficient biomass gasification via torrefaction. Energy, 31, pp. 3458-3470, 2006.

[6] Huber, G.W., Iborra, S. \& Corma, A., Synthesis of transportation fuels from biomass: chemistry, catalysts, and engineering. Chemical Reviews, 106, pp. 4044-4098, 2006.

[7] Ptasinski, K.J., Efficiency analysis of production of modern energy carriers from renewable resources and wastes. Ecosystems and Sustainable Development VI, eds. E. Tiezzi, J.C. Marques, C.A. Brebbia \& S.E. Jørgensen, WIT Press: Southampton, Boston, pp. 239-249, 2007.

[8] Rosen, M.A. \& Scott, D.S., Comparative efficiency assessments for a range of hydrogen production processes. International Journal of Hydrogen Energy, 23, pp. 653-659, 1998. 